\title{
Thermodynamic stability and kinetic inertness of a Gd-DTPA bisamide complex grafted onto gold nanoparticles
}

\section{Vijetha Mogilireddy ${ }^{a}$, Isabelle Déchamps-Olivier ${ }^{a}$, Christophe Alric ${ }^{b}$, Gautier Laurent ${ }^{c}$, Sophie Laurent ${ }^{d}$, Luce Vander Elst ${ }^{d, e}{ }^{\text {, }}$, Robert Muller ${ }^{d, e}$, Rana Bazzi ${ }^{c}$, Stéphane Roux ${ }^{c}$, Olivier Tillement ${ }^{b}$ and Françoise Chuburu ${ }^{a *}$}

\begin{abstract}
Gold nanoparticles coated by gadolinium (III) chelates (Au@DTDTPA) where DTDTPA is a dithiolated bisamide derivative of diethylenetriamine- $N, N, N^{\prime}, N^{\prime \prime}, N^{\prime \prime}$-pentaacetic acid (DTPA), constituted contrast agents for both X-ray computed tomography and magnetic resonance imaging. In an MRI context, highly stable $\mathrm{Gd}^{3+}$ complexes are needed for in vivo applications. Thus, knowledge of the thermodynamic stability and kinetic inertness of these chelates, when grafted onto gold nanoparticles, is crucial since bisamide DTPA chelates are usually less suited for Gd ${ }^{3+}$ coor- $^{-}$ dination than DTPA. Therefore, these parameters were evaluated by means of potentiometric titrations and relaxivity measurements. The results showed that, when the chelates were grafted onto the nanoparticle, not only their thermodynamic stability but also their kinetic inertness were improved. These positive effects were correlated to the chelate packing at the nanoparticle surface that stabilized the corresponding $\mathrm{Gd}^{3+}$ complexes and greatly enhanced their kinetic inertness. Copyright $\odot 2014$ John Wiley \& Sons, Ltd.
\end{abstract}

Additional supporting information may be found in the online version of this article at the publisher's web site.

Keywords: imaging agents; gadolinium chelates; nanoparticles; thermodynamics; kinetics

\section{INTRODUCTION}

Since its beginning in medical imaging, magnetic resonance imaging (MRI) has become an irreplaceable tool in diagnostic medicine. The reason of its success is based on the images obtained with excellent soft tissue contrast that allow anatomy assessment with an excellent spatial resolution. This noninvasive technique can also provide information on the physicochemical state of tissues, their vascularization and their function $(1,2)$. MRI relies on the longitudinal $\left(T_{1}\right)$ and transverse $\left(T_{2}\right)$ proton relaxation times of mainly water. The intrinsic relaxation times of tissue water are dependent on the physiological environment, so that differences in proton relaxation times within and among tissues are the source of contrast in MR images. In many clinical situations, the use of imaging agents allows better contrast to be obtained between healthy and pathological tissues. MRI contrast agents are not directly visualized in the image but only their effects are observed. The role of these agents is to shorten the longitudinal $\left(T_{1}\right)$ and/or transverse $\left(T_{2}\right)$ relaxation time of protons. Paramagnetic metals such as chelated gadolinium (III) ion have a strong effect on $T_{1}$ relaxation while superparamagnetic nanoparticles affect the $T_{1}$ and $T_{2} / T_{2}{ }^{*}$ relaxation times. The consequence is an improvement of the contrast between tissues. Recently, many papers have emphasized the development of nanoparticles as contrast agents (3). The advantages of the nanoparticles over the molecular contrast agents lies in their ability to amplify the MRI response (4), but also to gather in the same object several complementary properties. This attractive feature led to the development of multifunctional nanoparticles that can be detected by several in vivo imaging techniques. Among the numerous possibilities, combining MRI and X-ray computed tomography $(\mathrm{CT})$ is an attractive solution because not only are these modalities widely available in hospitals, but they also are complementary from a diagnostic point of view. It is therefore necessary to develop nanoparticles that could behave as contrast agents for both X-ray imaging and MRI. Designing such nanoparticles implies association within a nano-object, gadolinium (III) chelates as MRI contrast agents and high atomic number elements as contrast agents for X-ray CT imaging. In this context,

\footnotetext{
* Correspondence to: F. Chuburu, Institut de Chimie Moléculaire de Reims, CNRS UMR 7312, UFR des Sciences Exactes et Naturelles, Bâtiment 18, Europol'Agro, BP 1039, 51687 REIMS Cedex 2, France. E-mail: francoise.chuburu@univ-reims.fr

a V. Mogilireddy, I. Déchamps-Olivier, F. Chuburu Institut de Chimie Moléculaire de Reims, CNRS UMR 7312, UFR des Sciences Exactes et Naturelles, Bâtiment 18, Europol'Agro, BP 1039, 51687 REIMS Cedex 2, France

b C. Alric, O. Tillement Laboratoire de Physico-Chimie des Matériaux Luminescents, UMR CNRS 5620, Université Claude Bernard Lyon 1, 69622 Villeurbanne Cedex, France

c G. Laurent, R. Bazzi, S. Roux Institut UTINAM, UMR 6213 CNRS, Université de Franche-Comté, 25030 BESANCON, France

\section{d S. Laurent, L. Vander Elst, R. Muller}

University of Mons-Hainaut, NMR and Molecular Imaging Laboratory, Department of General, Organic and Biomedical Chemistry, B-7000 Mons, Belgium

e L. Vander Elst, R. Muller

Center for Microscopy and Molecular Imaging, 6041 Gosselies, Belgium
} 
gold nanoparticles were efficiently applied in vivo as X-ray contrast agents, because of the high atomic number of gold and high atomic absorption coefficient towards X-rays (5). Recently, gold nanoparticles functionalized by gadolinium (III) chelates were proposed as a bimodal contrast agent for CT/MRI (6-8). These particles were obtained by reducing a gold salt (9) in the presence of a dithiolated derivative of DTPA, namely DTDTPA (Scheme 1).

The ligand DTDTPA is a modified DTPA ligand for which two carboxylic functions were replaced by two amidothiol functions. If this modification is required to ensure the ligand grafting onto the gold nanoparticle, the thermodynamic stability and the kinetic inertness of the Gd-DTDTPA complex are expected to be lower since amido functions are less suited to a strong $\mathrm{Gd}^{3+} \mathrm{co}-$ ordination (10). Now, highly stable complexes are needed for in vivo applications to avoid problems associated with the release of toxic gadolinium (III) ions and development of $\mathrm{Gd}^{3+}$-related pathology (nephrogenic systemic fibrosis or NSF). Thus, in this context, it is necessary to determine the overall stability constants of DTDTPA (Scheme 1) and Au@DTDTPA (Scheme 1) towards $\mathrm{Gd}^{3+}$, and to evaluate the kinetic inertness of these two systems. In this work, we used potentiometric titrations to determine the Gd-DTDTPA and Gd-Au@DTDTPA stability constants by comparison with Gd-DTPA ones (Scheme 1) and we compared these constants with the ones determined towards potentially exchanging metals such as $\mathrm{Zn}^{2+}$ or $\mathrm{Ca}^{2+}$. We also evaluate by means of relaxometric measurements the kinetic inertness of Gd-DTDTPA and Gd-Au@DTDTPA (11).

\section{RESULTS AND DISCUSSION}

\subsection{DTDTPA and Au@DTDTPA Syntheses}

As previously reported, DTDTPA was synthesized by addition of aminoethanethiol on diethylenetriaminepentacetic acid bis (anhydride) DTPA-BA in DMF, in the presence of triethylamine (6). The chelate-coated gold nanoparticles (Au@DTDTPA-Gd) were synthesized as previously reported (6-8) by reducing a gold salt $\left(\mathrm{HAuCl}_{4} \cdot 3 \mathrm{H}_{2} \mathrm{O}\right)$ with sodium borohydride $\left(\mathrm{NaBH}_{4}\right)$ in the presence of DTDTPA (Scheme 1).

\subsection{Acid-Base Behavior of DTDTPA and Au@DTDTPA}

The acid-base behavior of DTDTPA and Au@DTDTPA was investigated through potentiometric titrations at $25 \pm 0.1^{\circ} \mathrm{C}$ by adding $\mathrm{NMe}_{4} \mathrm{OH} 0.1 \mathrm{moll}^{-1}$. The ionic strength was adjusted to 0.1 with $\mathrm{NMe}_{4} \mathrm{Cl}$, the presence of hydrochloric acid allowing the protonation of the ligand. Protometric titrations could be depicted as curves of $\bar{h}$ vs pH (Fig. 1), where $\bar{h}$ is the average number of protons bounded per mole of ligand.

For DTDTPA ( $\mathrm{LH}_{5}$ in its neutral form), this curve showed a plateau in the $\mathrm{pH}$ range $5-8$ for a $\bar{h}$ value of 3 . This indicated that, in this range, a sole triprotonated species $\mathrm{LH}_{3}^{2-}$ existed, which then could be stepwise deprotonated three times upon $\mathrm{pH}$ increase. For Au@DTDTPA ( $\mathrm{LH}_{3}$ in its neutral form), no plateau could be observed in this range, which indicated that for a grafted DTDTPA ligand, several species could co-exist in this $\mathrm{pH}$ range. The mathematical treatment of these data with PROTAF software (12) allowed the determination of DTDTPA and Au@DTDTPA protonation constants [equation (2)] and the corresponding $\log K_{01 \mathrm{~h}}$ values are collected in Table 1. For DTDTPA, six protonation constants were determined. To analyze the protonation pattern of DTDTPA, the values determined for this ligand were compared with $\log K_{01 \mathrm{~h}}$ values of relevant ligands such as DTPA-BMA (13) (Table 1) or some thiolated ligands. A survey of a stability constants database (14) indicated that thiol functions exhibit higher protonation constants than amino groups. For instance, for 1, 2-ethanedithiol, they are respectively 10.43 and 9.00 (15), while for dimercaptosuccinic acid, thiol protonation constants are respectively 9.54 and 12.05 (16). For DTDTPA, the two first values $\left(\log K_{011}=10.37\right.$ and $\log K_{012}=9.77$, Table 1$)$ were similar to the protonation constants of this dithiol, suggesting that these two steps could be assigned to successive ionic equilibria

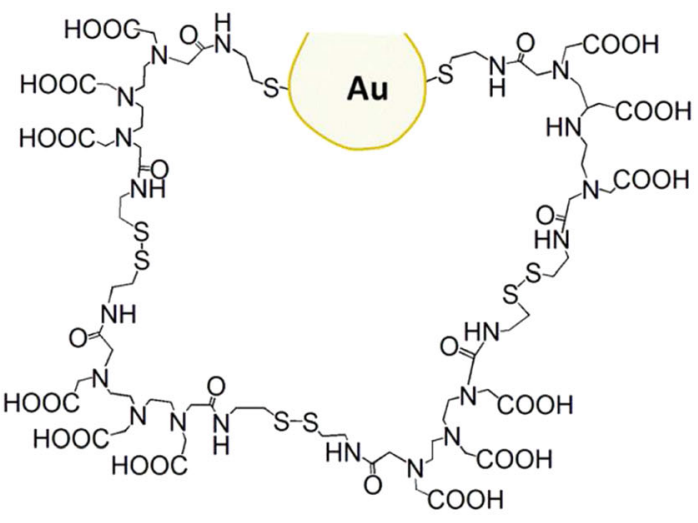

Au@DTDTPA<smiles>O=C(O)CN(CCN(CC(=O)O)CC(=O)O)CC(=O)O</smiles>

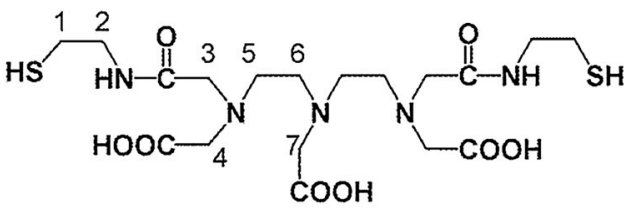

DTDTPA<smiles>CNC(=O)CN(CCN(CC(=O)O)CC(=O)O)CCN(CC(=O)O)CC(=O)O</smiles>

Scheme 1. Ligands DTDTPA, Au@DTDTPA [adapted from reference (6)], DTPA-BMA and DTPA. 


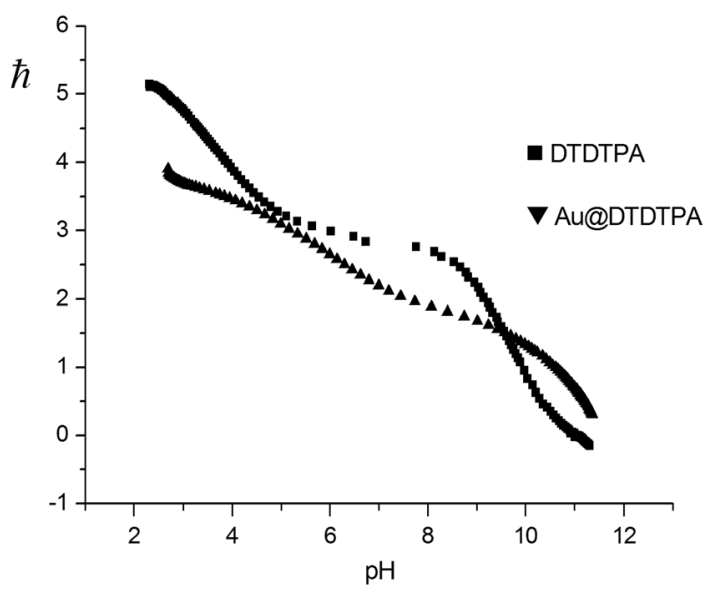

Figure 1. Average number $\bar{h}$ of protons bound per mole of DTDTPA (solid square) and Au@DTDTPA (solid triangle) as a function of $\mathrm{pH}$.

involving the two pendant RSH functions, successively deprotonated in two $\mathrm{RS}^{-}$functions. This proposal can be supported by ${ }^{1} \mathrm{H}$ NMR titration (Fig. 2). It is generally assumed that, when protonation occurs at a given nitrogen atom of a polyamine backbone, the ${ }^{1} \mathrm{H}$ borne by the carbons in $\alpha$ position to the nitrogen atom undergoes a downfield shift (17). From $12>$ $\mathrm{pH}>8$ the $\mathrm{H}_{1}$ protons (Scheme 1) underwent a downfield shift from 2.3 to $2.7 \mathrm{ppm}$, in accordance with $\mathrm{p} K_{\mathrm{a}}$ values determined by potentiometry. The four following constants could then involve the protonable sites of the DTPA bisamide backbone. For DTPA bisamides derivatives (13) and DTPA (14), it is well established that protonation equilibria measured in the $\mathrm{pH}$ range 9.5-3 take place at the backbone nitrogen atoms of the ligands. Thus for DTPA-BMA (13), the first proton ( $\log K_{011}=9.4$, Table 1) is added at the central nitrogen atom $\mathrm{N}_{\mathrm{c}}$ (Scheme 1) while the second $>\left(\log K_{012}=4.4\right)$ and the third $\left(\log K_{013}=3.1\right)$ are added at the terminal nitrogen atoms $\left(\mathrm{N}_{\mathrm{t}}\right.$, Scheme 1) (13). One should then observe that, for bisamide DTPA derivatives, a large $\Delta \log K_{12}=\log K_{011}-\log K_{012}$ value is expected and this difference is greatly superior to the one in the parent DTPA ligand $\left(\Delta \log K_{12}=10.41-8.37\right)$. For DTDTPA, this criterion is fulfilled between $\log K_{013}$ (8.96) and $\log K_{014}(4.79)$ This result, similar to what was measured for DTPA bisamide conjugate of penicillamine grafted onto Au nanoparticles $(18,19)$, suggested that the third proton was added on the central nitrogen atom of DTDTPA. ${ }^{1} \mathrm{H}$ NMR titration supported this assumption since the addition

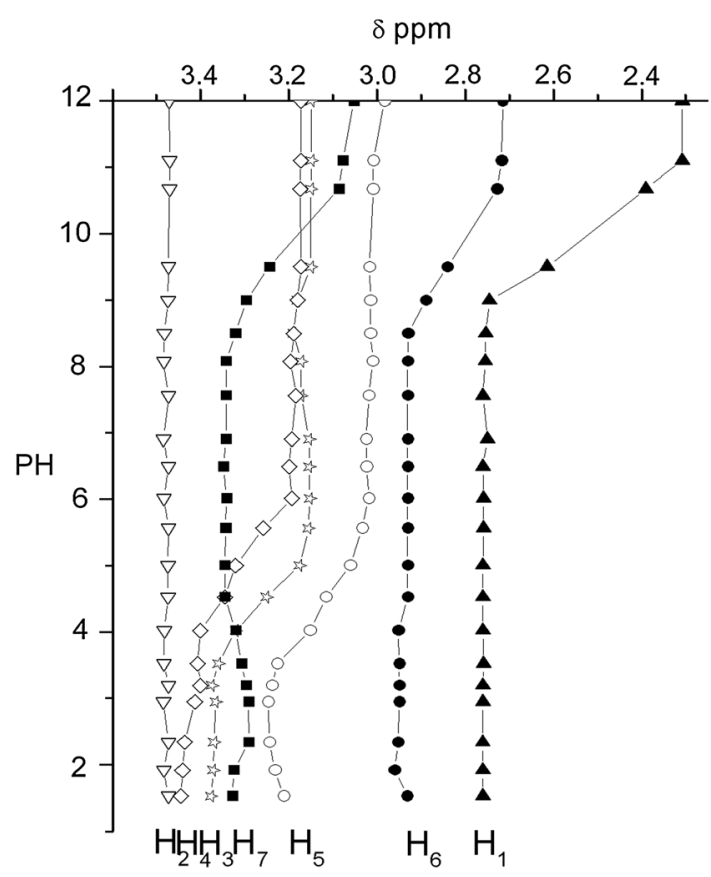

Figure 2. ${ }^{1} \mathrm{H}$ NMR titration of DTDTPA.

of the third proton $(10>\mathrm{pH}>8)$ was accompanied by the simultaneous downfield shifts of $\mathrm{H}_{6}$ and $\mathrm{H}_{7}$ (Fig. 2). Concerning $\log K_{014}$ and $\log K_{015}$ protonation events, they could be assigned to the terminal backbone nitrogen atoms, ${ }^{1} \mathrm{H}$ NMR titration indicating that the addition of the two corresponding protons (6> pH $>3$ ) induced a downfield shift for $\mathrm{H}_{3}, \mathrm{H}_{4}$ and $\mathrm{H}_{5}$ resonances. Finally, the last constant ( $\left.\log K_{016}\right)$ could be attributed to the protonation of a carboxylate oxygen. By analogy with DTPA bisamide derivatives, one can propose that this carboxylate group could be borne by the central backbone nitrogen. On the basis of these propositions, the protonation pattern of DTDTPA could be described as in Scheme 2.

For Au@DTDTPA, five protonation constants were determined. FT-IR and XPS analysis of Au@DTDTPA (6) revealed that DTDTPA is anchored at the nanoparticle surface by one thiol group and the unreacted thiols established disulfide bonds between neighboring DTDTPA (Scheme 1). As a result, DTDTPA led to the formation of a multilayered ligand shell (6). Owing to DTDTPA packing at the nanoparticle surface, all the protonation events that could be determined by potentiometry experiments are

\begin{tabular}{|c|c|c|c|c|}
\hline $\log K_{01 \mathrm{~h}}$ & DTDTPA & DTPA-BMA & Au@DTDTPA & DTPA $^{b}$ \\
\hline$[\mathrm{LH}] /[\mathrm{L}]\left[\mathrm{H}_{3} \mathrm{O}^{+}\right]$ & $10.37(2)$ & 9.4 & $11.26(3)$ & 10.41 \\
\hline$\left[\mathrm{LH}_{2}\right] /[\mathrm{LH}]\left[\mathrm{H}_{3} \mathrm{O}^{+}\right]$ & $9.77(1)$ & 4.4 & $10.12(2)$ & 8.37 \\
\hline$\left[\mathrm{LH}_{3}\right] /\left[\mathrm{LH}_{2}\right]\left[\mathrm{H}_{3} \mathrm{O}^{+}\right]$ & $8.96(2)$ & 3.1 & $7.27(3)$ & 4.09 \\
\hline$\left[\mathrm{LH}_{4}\right] /\left[\mathrm{LH}_{3}\right]\left[\mathrm{H}_{3} \mathrm{O}^{+}\right]$ & $4.79(1)$ & - & $5.75(2)$ & 2.51 \\
\hline$\left[\mathrm{LH}_{5}\right] /\left[\mathrm{LH}_{4}\right]\left[\mathrm{H}_{3} \mathrm{O}^{+}\right]$ & $3.43(1)$ & - & $3.78(1)$ & 2.04 \\
\hline$\left[\mathrm{LH}_{6}\right] /\left[\mathrm{LH}_{5}\right]\left[\mathrm{H}_{3} \mathrm{O}^{+}\right]$ & $2.34(1)^{c}$ & - & - & - \\
\hline$\Sigma \log K_{01-5}$ & 37.32 & 15.78 & 38.18 & 27.42 \\
\hline \multicolumn{5}{|c|}{$\begin{array}{l}{ }^{\mathrm{a}} \text { Reference }(13)(0.1 \mathrm{M} \mathrm{NaCl}) ; \\
{ }^{\mathrm{b}} \text { reference }(14)(0.1 \mathrm{M} \mathrm{KCl}) ; \\
{ }^{\mathrm{c}} \text { not included in } \Sigma \text { log } K_{01-5} \text { calculation. }\end{array}$} \\
\hline
\end{tabular}


<smiles>O=C([O-])CN(CCN(CCN(CC(=O)[O-])CC(=O)NCCS)CC(=O)NCCS)CC(=O)[O-]</smiles>

$\mathrm{L}^{6-}$<smiles>O=C(O)C[NH2+]CC[NH2+]CC(=O)N[CH+]CC(=O)NCC(=O)NCCS</smiles>

$\mathrm{LH}_{6}{ }^{+}$<smiles>O=C([O-])CN(CCN(CC(=O)[O-])CC(=O)NCCS)CCN(CC(=O)[O-])CC(=O)NCCS</smiles>

$\mathrm{LH}^{5-}$<smiles>O=C([O-])CN(CCNC(=O)CN(CCN(CC(=O)[O-])CC(=O)NCCS)CC(=O)[O-])CC(=O)O</smiles>

118.96

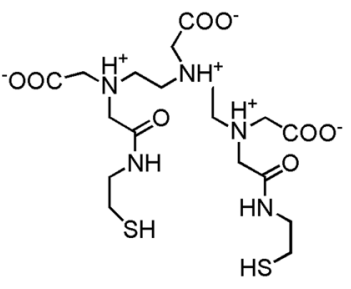

$\mathrm{LH}_{5}$
3.43<smiles>O=C([O-])C[NH+](CCN[CH+]CC(=O)O[Na])CC(=O)NCC(=O)NCC(=O)NCCS</smiles>

$\mathrm{LH}_{4}^{-}$<smiles>O=C([O-])CN(CCN[PH2+]CCN(CC(=O)[O-])CC(=O)NCCS)CC(=O)NCCS</smiles>

$\mathrm{LH}_{3}{ }^{2-}$

Scheme 2. Protonation pattern of DTDTPA.

the result of overall proton exchanges. Therefore, these equilibria are studied by measuring the average number of protons released for a fixed amount of grafted nanoparticles.

Comparison of Au@DTDTPA backbone nitrogen atom deprotonation constant values ( $\log K_{011}$ to $\log K_{013}$ ) with those of DTDTPA showed that, in a general trend, the basicity of the amino nitrogen atoms increased when the ligand was anchored at the nanoparticle surface. This basicity enhancement could be interpreted as the result of $\mathrm{H}$-bonds between the added protons and all the acido-basic sites. Indeed, owing to the ligand packing at the nanoparticle surface, these sites were spread all around the nano-object and could stabilize these protons. These results were similar to the ones reported for polyaminocarboxylate ligands embedded on the surface of macromolecules, for which the existence of an extended hydrogen bond network alters the overall charge distribution at the vicinity of these ligands and modifies their basicity (20). As a consequence, the identification of the protonation sites at the surface of the functionalized nanoparticle, that is to say a site-specific description of the nanoparticle protonation, was rather speculative since, first, the accessibility of acido-basic functions was probably not homogenous at the surface and second, successive additions of protons were probably followed by ligand reorganization at the surface (21).

\subsection{Stability Constants and Thermodynamic Stability of DTDTPA:Gd and Au@DTDTPA:Gd}

To evaluate the thermodynamic stability of $\mathrm{Gd}^{3+}$ complexes with DTDTPA and Au@DTDTPA, the overall stability constants of DTDTPA:Gd and Au@DTDTPA:Gd systems were determined by potentiometry. For DTDTPA:Gd ${ }^{3+}$ system (Fig. 3), the comparison of $\bar{h} \mathrm{vs} \mathrm{pH}$ curves for the ligand alone and in the presence of $\mathrm{Gd}^{3+}$ ions (metal-to-ligand ratio $R \approx 1$ ) showed that, in the presence of $\mathrm{Gd}^{3+}$, the titration curve was depressed relative to the titration curve of the ligand alone. This deviation revealed complex formation from $\mathrm{pH}$ 2.5. The DTDTPA:Gd ${ }^{3+}$ curve presented a plateau for $4<\mathrm{pH}<8$ and $\mathrm{pH}>11$ for $\bar{h}=2$ and 0 , respectively. The first plateau corresponded to the existence in solution of a diprotonated complex $\left(\mathrm{GdLH}_{2}\right.$ species) while the second one could be correlated with the existence of a deprotonated species

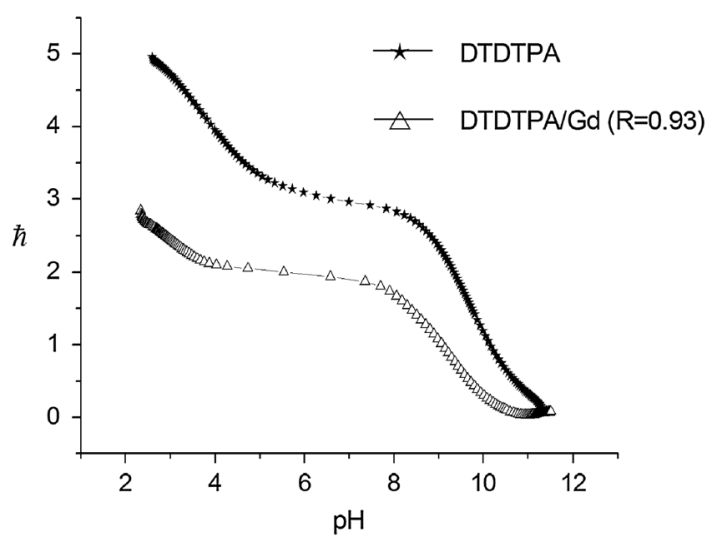

Figure 3. Average number $\bar{h}$ of protons bound per mole of DTDTPA $\left({ }^{*}\right)$ and DTDTPA:Gd (open triangle) as a function of $\mathrm{pH}$.

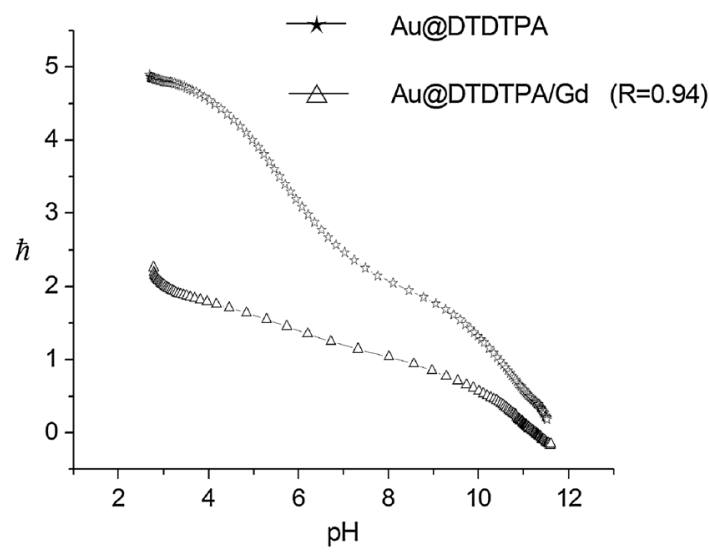

Figure 4. Average number $h$ of protons bound per mole of Au@DTDTPA $\left.{ }^{*}\right)$ and Au@DTDTPA:Gd (open triangle) as a function of $\mathrm{pH}$.

$\left(\mathrm{GdL}^{2-}\right)$. For the Au@DTDTPA:Gd ${ }^{3+}$ system (Fig. 4), the comparison of $\bar{h} \mathrm{vs} \mathrm{pH}$ curves for the grafted Au nanoparticle alone and in the presence of $\mathrm{Gd}^{3+}$ ions $(R \approx 1)$ showed that complexation occurred also from $\mathrm{pH} 2.5$. The shape curve between $6<\mathrm{pH}<9$ 


\begin{tabular}{|c|c|c|}
\hline $\log \beta_{\mathrm{m} 1 \mathrm{~h}}$ & $\mathrm{~L}=\mathrm{DTDTPA}$ & L=Au@DTDTPA \\
\hline $\mathrm{L}+2 \mathrm{H}^{+}+\mathrm{Gd}^{3+}=\mathrm{GdLH}_{2}$ & $34.94(4)$ & $35.6(2)$ \\
\hline $\mathrm{L}+\mathrm{H}^{+}+\mathrm{Gd}^{3+}=\mathrm{GdLH}$ & $26.41(5)$ & $31.7(2)$ \\
\hline $\begin{array}{l}\mathrm{L}+\mathrm{Gd}^{3+}=\mathrm{GdL} \\
\log K_{\mathrm{m} 1 \mathrm{~h}}\end{array}$ & $16.46(5)$ & $21.2(2)$ \\
\hline $\mathrm{GdL}+\mathrm{H}=\mathrm{GdLH}$ & 9.95 & 10.5 \\
\hline $\mathrm{GdLH}+\mathrm{H}=\mathrm{GdLH}_{2}$ & 8.53 & 3.9 \\
\hline
\end{tabular}

for an $\bar{h}$ value of 1 suggested the existence in solution of a monoprotonated complex (Au@GdLH ${ }^{+}$species). Data analysis by PROTAF software (12) indicated that, for DTDTPA:Gd ${ }^{3+}$ and Au@DTDTPA: $\mathrm{Gd}^{3+}$ systems, the best curve fitting is obtained by assuming the formation of $\mathrm{GdLH}_{2}, \mathrm{GdLH}$ and $\mathrm{GdL}$ complexes (charges of the complexes omitted here for clarity), whose overall formation constants are reported in Table 2. DTDTPA exhibited eight potential donor atoms to coordinate $\mathrm{Gd}^{3+}$ and the similarity of the two successive deprotonation constant values of $\mathrm{GdLH}_{2}(\log K=9.95$ and 8.57) with the two first deprotonation constants of DTDTPA alone (log $K_{011}=10.37$ and $\log K_{012}=9.77$ ) suggested that, in $\mathrm{GdLH}_{2}$, the successive deprotonations into $\mathrm{GdLH}^{-}$and $\mathrm{GdL}^{2-}$ involved the thiol functions. These functions are not expected to coordinate to the $\mathrm{Gd}^{3+}$ ion (22). However, the two deprotonation $\mathrm{SH} / \mathrm{S}^{-}$equilibria occurred at lower $\mathrm{pH}$ in DTDTPA:Gd than in the ligand alone, which could be interpreted as an assistance of the metal to the complex deprotonation. The species distribution diagrams of DTDTPA:Gd and Au@DTDTPA:Gd systems are reported in Fig. 5. It was also important to compare the stability of these $\mathrm{Gd}$ complexes with the ones of potentially competitive endogenous ions such as $\mathrm{Zn}^{2+}$ and $\mathrm{Ca}^{2+}$. It is indeed well known that $\mathrm{Zn}^{2+}$ ions can behave as an exchanging metal towards $\mathrm{Gd}^{3+}(11,23)$. In addition, $\mathrm{Ca}^{2+}$ and $\mathrm{Gd}^{3+}$ possess similar ionic radii, leading to potential exchanges in vivo (24). The overall complexation constants of DTDTPA:M and Au@DTDTPA:M with $\mathrm{M}=\mathrm{Zn}^{2+}$, and $\mathrm{Ca}^{2+}$ are reported in Tables $\mathrm{S} 1$ and $\mathrm{S} 2$ (Supporting Information). The trend of increasing complex stability is $\mathrm{Ca}^{2+}<\mathrm{Zn}^{2+}<\mathrm{Gd}^{3+}$. One should note that, for DTDTPA:Ca systems, thiol groups are not expected to coordinate $\mathrm{Ca}^{2+}$ and their deprotonation should not be significantly influenced by the coordination of $\mathrm{Ca}^{2+}$ to the ligand. Indeed, from $\mathrm{pH}$-potentiometric titrations two constants corresponding to $\log K_{\mathrm{CaLH}}=10.2$ and $\log K_{\mathrm{CaLH} 2}=8.9$ were obtained (Table S2, Supporting Information), values relatively close to the log $K_{011}=10.37$ and $\log K_{012}=9.77$ (Table 1) determined for the ligand itself.

To circumvent the different protonated states of the complexes, an efficient way to compare the sequestering ability of DTDTPA and Au@DTDTPA for all these ions was to determine the logarithmic amount of free metal relative to the metal coordinated on the whole $\mathrm{pH}$ range. Thus, the smallest the logarithmic value is, the higher is the affinity of the ligand for the metal ion. For $\mathrm{Gd}^{3+}$ first (Fig. 6), the DTDTPA:Gd complex was less stable than Au@DTDTPA:Gd, this latter being 2 orders of magnitude more stable at physiological $\mathrm{pH}$. This result was in the expected relation to the previously measured enhancement of DTDTPA basicity when it was grafted on the Au nanoparticle. Second, the comparison of DTDTPA and Au@DTDTPA affinities for the three metal ions (Fig. 7) indicated that for each of them the best affinity was obtained for $\mathrm{Gd}^{3+}$, which is a crucial point for the use of these systems as MRI contrast agents.
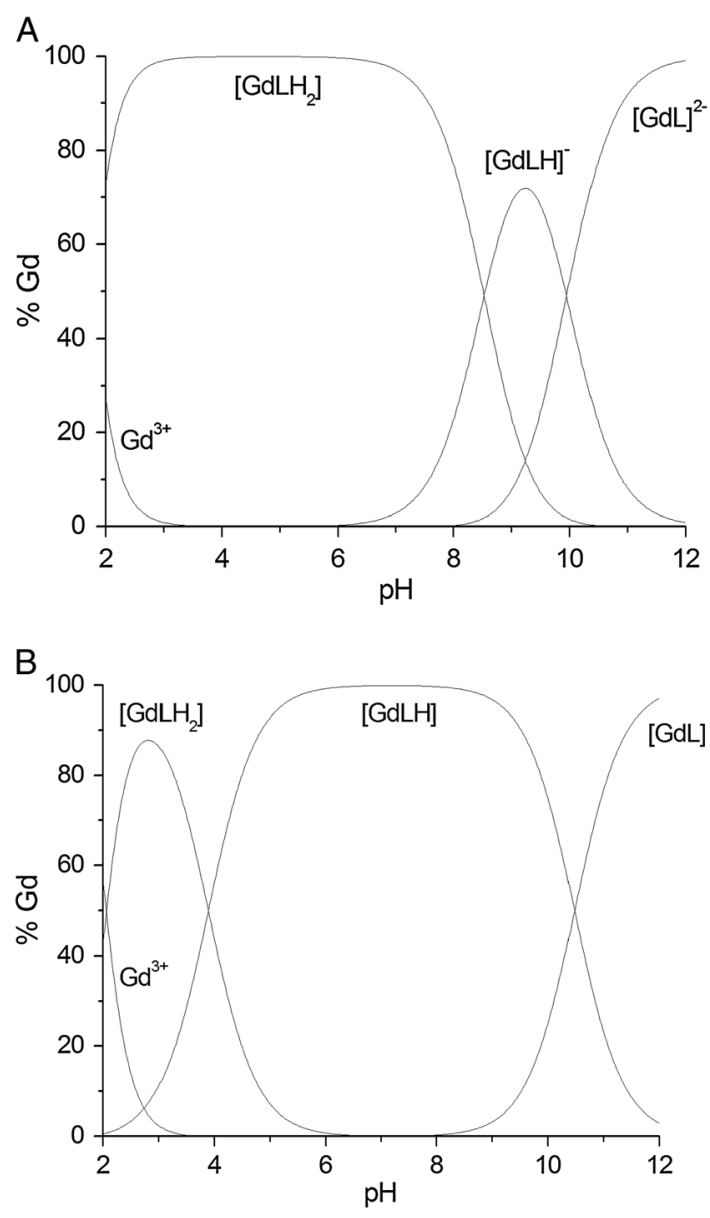

Figure 5. Species distribution diagrams for $\mathrm{Gd}(\mathrm{III})$ complexes with (a) DTDTPA, (b) Au@DTDTPA $\left(C_{\mathrm{L}}=C_{\mathrm{M}}=2.0 \times 10^{-3} \mathrm{moll}^{-1}\right)$.

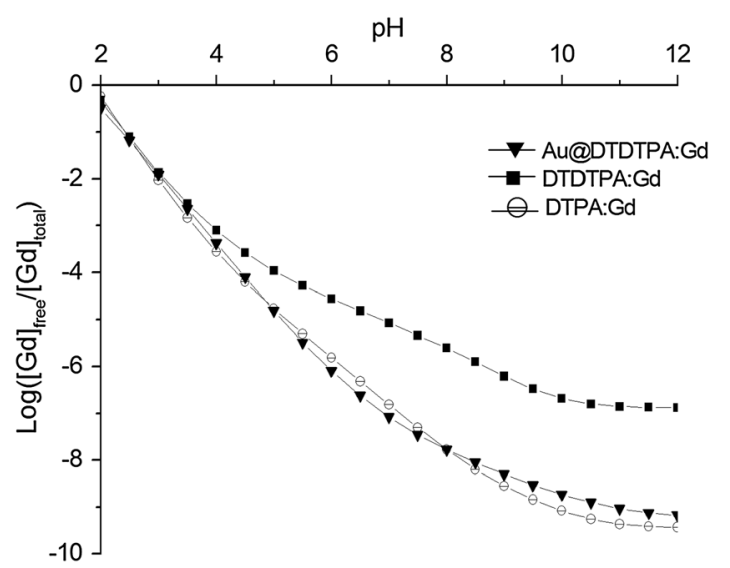

Figure 6. [Gd]free/[Gd]total for DTDTPA and Au@DTDTPA systems in comparison with DTPA.

\subsection{Transmetallation of DTDTPA:Gd and Au@DTDTPA:Gd}

Since both $\mathrm{Gd}^{3+}$ and polyaminocarboxylate ligands are toxic, DTDTPA:Gd and Au@DTDTPA:Gd must have high kinetic inertness, which means that the extent of their dissociation in the body has to be practically negligible. The previous results indicated that overall stability constants of $\mathrm{Zn}^{2+}$ complexes were close to those of $\mathrm{Gd}^{3+}$, suggesting that $\mathrm{Zn}^{2+}$ could act as an 
A

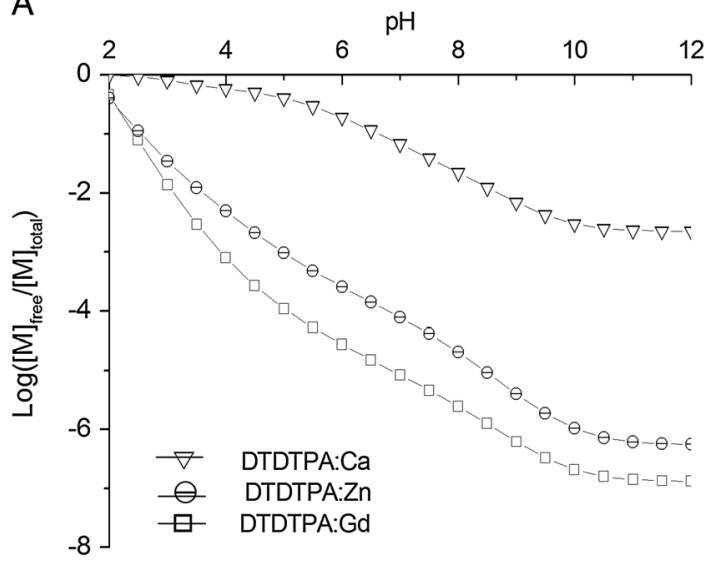

B

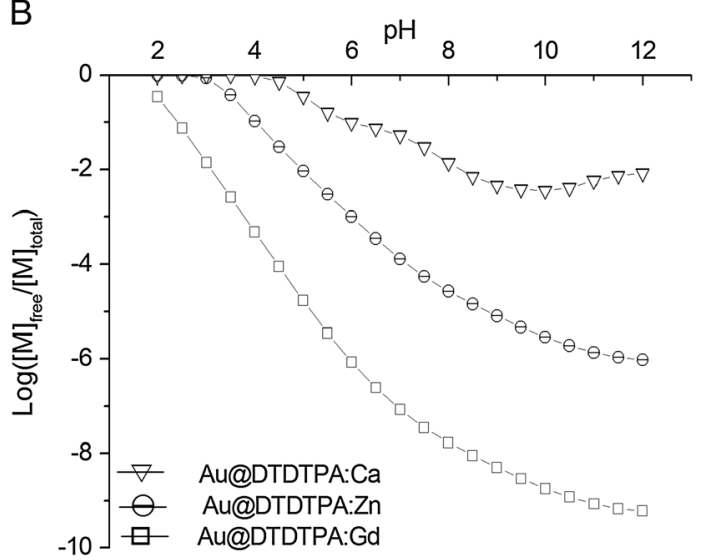

Figure 7. $[\mathrm{M}]_{\text {free }} /[\mathrm{M}]_{\text {total }}$ for (a) DTDTPA and (b) Au@DTDTPA systems with $M=G d(I I), Z n(I I)$ and $C a(I I)$.

exchanging metal in biological media. The kinetic stabilities of DTDTPA:Gd and Au@DTDTPA:Gd were characterized by the rate of their transmetallation reaction occurring in solution with $\mathrm{Zn}^{2+}$ ions and, for a direct comparison, the same method was used for DTPA:Gd. [The aim of the study being a direct comparison of the respective kinetic inertness of DTDTPA:Gd and Au@DTDTPA:Gd, exchange reactions with $\mathrm{Cu}(\mathrm{II})$ were not considered here. Actually, it was not possible to follow by UV-vis spectroscopy the transmetallation reaction with this ion in the case of Au@DTDTPA:Gd, because of strong absorption of the nanosuspension.] It has indeed been proposed that the kinetic stability of a $\mathrm{Gd}^{3+}$ chelate can be followed by relaxometry in the presence of $\mathrm{Zn}^{2+}$ in a phosphate-buffered solution (11). If the transmetallation reaction occurs, it will result in $\mathrm{Gd}^{3+}$ release which then will precipitate into $\mathrm{GdPO}_{4}$. Consequently, it will lead to a subsequent decrease of the proton paramagnetic relaxation rate $\left(R_{1 \mathrm{p}}\right)(11)$. DTDTPA:Gd and Au@DTDTPA:Gd $R_{1 \mathrm{p}}$ evolutions with time gave therefore a good estimation of transmetallation. Fig. 8 showed the evolution of their normalized paramagnetic relaxation rates $R_{1 \mathrm{p}}^{\mathrm{t}} / R_{1 \mathrm{p}}^{0}$ and compared them with those of DTPA: $\mathrm{Gd}$. A semi-quantitative evaluation of the transmetallation kinetics was performed by comparing the time needed to reach $80 \%$ of the initial $R_{1 \mathrm{p}}^{0}$ value. The shortest delay was obtained for DTDTPA:Gd $(110 \mathrm{~min})$ while for Au@DTDTPA:Gd the delay was similar to that measured for DTPA:Gd $(220 \mathrm{~min})$. These results favored the kinetic inertness of Au@DTDTPA:Gd system. A theoretical description was attempted to evaluate in the current experimental conditions the rate of transmetallation of the $\mathrm{Gd}^{3+}$

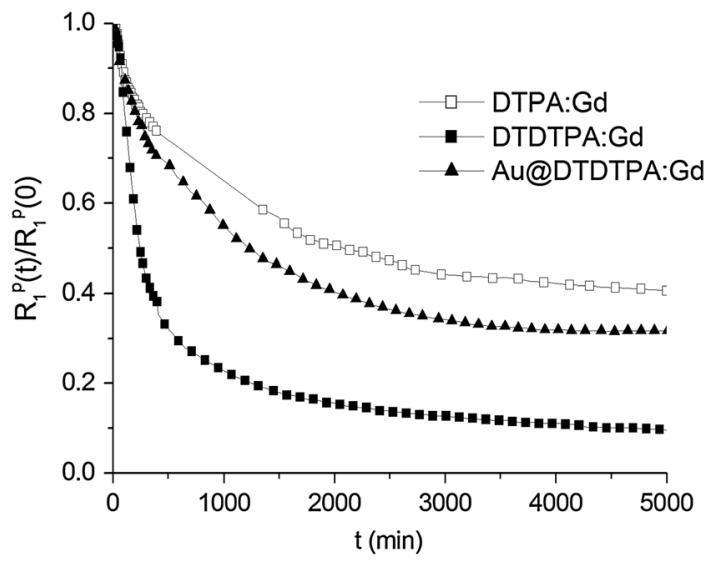

Figure 8. Evolution of $R_{1 \mathrm{p}}(t) / R_{1}^{\mathrm{p}}(0)$ vs time for DTPA:Gd, DTDTPA:Gd and Au@DTDTPA:Gd (initial concentrations of $\mathrm{Gd}$ complexes and $\mathrm{ZnCl}_{2}: 2.5$ $\mathrm{mM}$ in phosphate buffer $\mathrm{pH}=7, T=37^{\circ} \mathrm{C}, B=0.94 \mathrm{~T}$ ).

species and the $\mathrm{Gd}^{3+}$ species lifetimes [equations (4) and (5)]. The $k_{\text {obs }}$ values obtained by fitting the experimental data were $3.9 \times 10^{-3}$ and $2.7 \times 10^{-3} \mathrm{~min}^{-1}$ for DTDTPA:Gd and Au@DTDTPA:Gd, respectively, while for the reference DTPA:Gd this constant was $2.5 \times 10^{-3} \mathrm{~min}^{-1}$. Therefore, DTDTPA:Gd and Au@DTDTPA:Gd half-life values were 177 and 257 min, respectively, while for the reference DTPA:Gd the half-life was $277 \mathrm{~min}$. At the end of the observation period ( $\sim 3$ days) the ratio $R_{1 \mathrm{p}}^{\mathrm{t}} / R_{1 \mathrm{p}}^{0}$ was about $10 \%$ for DTDTPA:Gd compared with $50 \%$ for the reference DTPA:Gd. This indicated that the bisamide complex DTDTPA:Gd showed more extensive transmetallation than the parent compound. This behavior was consistent with what was already determined in GdDTPA bisamide series $(25,26)$. The reason for this lies in the substitution of two carboxylate groups by two amide groups in the first coordination sphere of $\mathrm{Gd}^{3+}$. For Au@DTDTPA:Gd the ratio of $R_{1 \mathrm{p}}^{\mathrm{t}} / R_{1 \mathrm{p}}^{0}$ was remarkably higher $(33 \%)$ and comparable to that of the reference DTPA:Gd. This indicated that, when DTDTPA:Gd is grafted onto the Au nanoparticle, its transmetallation tends to be reduced. This behavior was also reported in a bisamide DTPA series for which the amide hydrogen atoms were gradually substituted with butyl groups, which induced a steric hindrance at the vicinity of the Gd center (27). The similar result obtained here suggested that the bulky nanoparticle rigidified the structure of the complex and

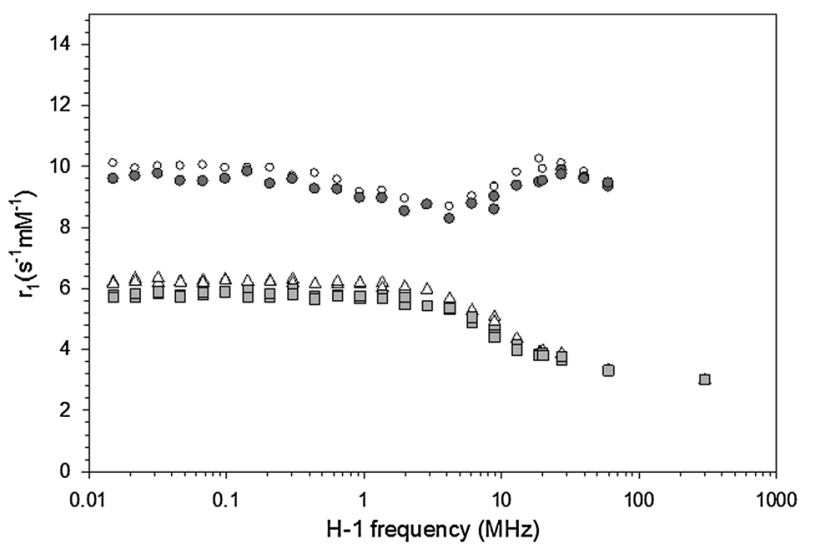

Figure 9. NMRD profile of Au@DTDTPA:Gd nanoparticles: (open circle) $t=0$; (solid circle) $s=7$ days later $\left[\right.$ Magnevist ${ }^{\oplus}$ (open triangle) and GdDTDTPA (solid circle) NMRD profiles are given for comparison.] 
prevented grafted DTDTPA:Gd complexes from extensive demetallation. To follow the nanosuspension relaxivity, NMRD profiles of a nanosuspension for which a third of DTDTPA ligands were complexed were recorded over a period of 7 days (Fig. 9). Compared with DTDTPA:Gd and DTPA:Gd complexes, these profiles were characterized by a maximum in relaxivity between 10 and $100 \mathrm{MHz}$ typical of slowly rotating complexes of $\mathrm{Gd}^{3+}$. Furthermore, the perfect superimposition of the two profiles for Au@DTDTPA:Gd at days 0 and 7 highlighted that no $\mathrm{Gd}^{3+}$ leakage could be detected. This result showed the very good stability of this nanosuspension. Moreover, since Au@DTDTPA:Gd elimination by renal filtration is rapid ( $25 \mathrm{~min}$ after intravenous injection) (7), this result constitutes a positive argument for the use of these nanoparticles in vivo.

\section{CONCLUSION}

Gold nanoparticles coated by a dithiolated bisamide ligand DTDTPA (Au@DTDTPA), elaborated for both X-ray and MRI imaging, have been evaluated in terms of thermodynamic stability and kinetic inertness of their $\mathrm{Gd}^{3+}$ complex. This study was motivated by the fact that stability and toxicity issues of Gd-based contrast agents might be associated with the use of certain DTPA-bisamide derivative $\mathrm{Gd}^{3+}$ complexes. For that reason, potentiometric titrations and relaxometric measurements were performed on DTDTPA alone, and Au@DTDTPA, and the results compared with those of the parent DTPA ligand. The decreased basicity of the backbone nitrogens brought by amide formation in DTDTPA was modified when the ligand was grafted on the Au nanoparticle, which resulted in an enhancement of the thermodynamic stability of the corresponding Au@DTDTPA:Gd complex by comparison with DTDTPA:Gd. Therefore, the grafted DTDTPA: Gd gained in stability, leading to a complex almost as stable as DTPA:Gd itself. Moreover, comparison of Au@DTDTPA affinity towards $\mathrm{Gd}^{3+}$-competitive ions, namely $\mathrm{Zn}^{2+}$ and $\mathrm{Ca}^{2+}$, showed that the best affinity was obtained for $\mathrm{Gd}^{3+}$. Transmetallation of Au@DTDTPA:Gd in the presence of $\mathrm{Zn}^{2+}$, the most abundant endogenous metal ion, was then undertaken to evaluate the kinetic stability of the metallated gold nanoparticle, close to physiological conditions. These conditions, although different from the in vivo ones, provided information concerning the in vivo kinetic behavior of the complexes. The stability of the immobilized chelates regarding transmetallation against $\mathrm{Zn}^{2+}$ was evaluated by relaxometric measurements using the protocol established for soluble $\mathrm{Gd}^{3+}$ chelates. The time evolution of Au@DTDTPA: Gd relaxivity suggested that transmetallation was a slightly perceptible than for DTPA:Gd. Nevertheless, the extent of the demetallation was distinctly less important than for the nongrafted DTDTPA:Gd and could be prevented by finding a good compromise between amounts of chelated $\mathrm{Gd}^{3+}$ at the nanoparticle surface and colloidal stability while providing an enhancement of relaxivity.

\section{EXPERIMENTAL}

\subsection{General}

\subsubsection{DTDTPA synthesis}

DTDTPA synthesis was previously described (6-8). In a round flask of $250 \mathrm{ml}, 2 \mathrm{~g}\left(5.6 \times 10^{-3} \mathrm{~mol}\right)$ of diethylenetriaminepentacetic acid bis-anhydride was dissolved in $40 \mathrm{ml}$ of dimethylformamide and then heated to $70^{\circ} \mathrm{C}$. In another flask, $1.4 \mathrm{~g}\left(1.23 \times 10^{-2} \mathrm{~mol}\right)$ of aminoethanethiol was dissolved in $30 \mathrm{ml}$ of DMF and $1.74 \mathrm{ml}$ of triethylamine. This solution was added to the round flask and stirring magnetically at $70^{\circ} \mathrm{C}$ overnight. Then, the solution was first cooled to room temperature and then put into an ice bath. A white powder $\left(\mathrm{NEt}_{3}, \mathrm{HCl}\right)$ precipitated and was filtered. The filtrate was concentrated at low pressure. After addition of this solution to a chloroform solution, a white precipitate was formed. After filtration of solution, washing with $50 \mathrm{ml}$ of chloroform and drying under vacuum, DTDTPA was obtained as white powder ( $90 \%$ yield).

${ }^{1} \mathrm{H}$ NMR (300 MHz, $\left.\mathrm{D}_{2} \mathrm{O}, 298 \mathrm{~K}\right): \delta 3.81$ (s, 4H, -N-CH $\left.-\mathrm{CO}-\mathrm{N}-\right)$, 3.69 (s, 4H, $\left.-\mathrm{N}-\mathrm{CH}_{2}-\mathrm{COOH}\right), 3.64\left(\mathrm{~s}, 2 \mathrm{H},-\mathrm{N}-\mathrm{CH}_{2}-\mathrm{COOH}\right), 3.38-3.20$ (m, $\left.12 \mathrm{H},-\mathrm{N}-\mathrm{CH}_{2}-\mathrm{CH}_{2}-\mathrm{SH},-\mathrm{N}-\mathrm{CH}_{2}-\mathrm{CH}_{2}-\mathrm{N}\right), 2.70\left(\mathrm{t}, 4 \mathrm{H}, \mathrm{N}-\mathrm{CH}_{2}-\mathrm{CH}_{2^{-}}\right.$ $\mathrm{SH}) .{ }^{13} \mathrm{C}$ NMR $\left(75 \mathrm{MHz}, \mathrm{D}_{2} \mathrm{O}, 298 \mathrm{~K}\right): \delta: 172.48$ and $172.18(-\mathrm{N}-$ $\left.\mathrm{CH}_{2}-\mathrm{COOH}\right), 168.93\left(-\mathrm{N}-\mathrm{CH}_{2}-\mathrm{CO}-\mathrm{N}\right), 57.17$ and $56.86\left(-\mathrm{N}-\mathrm{CH}_{2}-\right.$ $\mathrm{COOH}), 54.76\left(\mathrm{~N}-\mathrm{CH}_{2}-\mathrm{CO}-\mathrm{N}\right), 52.17$ and $51.55\left(-\mathrm{N}-\mathrm{CH}_{2}-\mathrm{CH}_{2}-\mathrm{N}-\right)$, $42.61\left(-\mathrm{N}-\mathrm{CH}_{2}-\mathrm{CH}_{2}-\mathrm{SH}\right), 23.68\left(-\mathrm{N}_{-} \mathrm{CH}_{2}-\mathrm{CH}_{2}-\mathrm{SH}\right)$.

IR: $2929\left(v_{\mathrm{CH}}\right.$, alkyl), $2530\left(v_{\mathrm{SH}}\right), 1718\left(v_{\mathrm{CO}}, \mathrm{COOH}\right), 1646\left(v_{\mathrm{CO}}\right.$, RCONR'R"), $1533\left(v_{\mathrm{CO}}, \mathrm{RCONHR}^{\prime}\right) \mathrm{cm}^{-1}$. The comparison of spectra of DTPA and DTDTPA show clearly the emergence of a characteristic peak for $v_{\mathrm{S}-\mathrm{H}}$ at $2530 \mathrm{~cm}^{-1}$. ES-MS (+): $\mathrm{m} / \mathrm{z}=512$ $\left([\mathrm{M}+\mathrm{H}]^{+}\right) ; 534.2\left([\mathrm{M}+\mathrm{Na}]^{+}\right)$.

\subsection{2. ${ }^{1} \mathrm{H} N M R$ titration}

The $\mathrm{pH}$ was adjusted by additions of small amounts of a $1 \mathrm{M}$ $\mathrm{NaOH}$ or $1 \mathrm{M} \mathrm{HCl}$ solution to $\mathrm{H}_{2} \mathrm{O}$ solutions (with $10 \% \mathrm{D}_{2} \mathrm{O}$ and 2,2-dimethyl-2-silapentane-5-sulfonate sodium salt as a calibration standard) containing DTDTPA $\left(1.3 \times 10^{-2} \mathrm{moll}^{-1}\right)$ under argon atmosphere. NMR measurements were performed on a Bruker Alll $600(600.16 \mathrm{MHz})$ after an equilibration time of 1 day.

\subsubsection{Au@DTDTPA:Gd synthesis}

For a typical preparation of gold particles (6-8), $200 \mathrm{mg}\left(51 \times 10^{-5} \mathrm{~mol}\right)$ of $\mathrm{HAuCl}_{4} 3 \mathrm{H}_{2} \mathrm{O}$, dissolved in $60 \mathrm{ml}$ of methanol, was placed in a $250 \mathrm{ml}$ round-bottom flask. A $256 \mathrm{mg}\left(50 \times 10^{-5} \mathrm{~mol}\right)$ aliquot of DTDTPA in $40 \mathrm{ml}$ of water and $2 \mathrm{ml}$ of acetic acid was added to the gold salt solution under stirring. The mixture turned from yellow to orange. After $5 \mathrm{~min}, 185 \mathrm{mg}\left(489 \times 10^{-5} \mathrm{~mol}\right)$ of $\mathrm{NaBH}_{4}$ dissolved in $14 \mathrm{ml}$ of water was added to the orange mixture under vigorous stirring at room temperature. At the beginning of the $\mathrm{NaBH}_{4}$ addition, the solution became first dark brown then a black flocculate appeared. The vigorous stirring was maintained for $1 \mathrm{~h}$ before adding $5 \mathrm{ml}$ of $1 \mathrm{M}$ aqueous hydrochloric acid solution. After the partial removal of the solvent under reduced pressure and at a maximum of $40^{\circ} \mathrm{C}$, the precipitate was filtered on a polymer membrane and washed thoroughly and successively with $0.01 \mathrm{M} \mathrm{HCl}$, water and diethylether. The resulting black powder (Au@DTDTPA) was dried and stocked in the solid state or dispersed in $10 \mathrm{ml}$ of $0.01 \mathrm{M} \mathrm{NaOH}$ solution (up to $200 \mathrm{mg}$ of dry powder).

\subsubsection{Au@DTDTPA:Gd $d_{50}$ synthesis}

For ${ }^{1} \mathrm{H}$ NMRD profile measurements, the ligand-to-metal ratio was fixed to $3 . \mathrm{Gd}^{3+}$ complexation was carried out through the addition of $\mathrm{GdCl}_{3}\left(102 \mu \mathrm{l}\right.$, $\left.\left[\mathrm{Gd}^{3+}\right]=135 \mathrm{mM}\right)$ on Au@DTDTPA colloidal solution $(2232 \mu \mathrm{l},[\mathrm{Au}]=45 \mathrm{mM})$ under stirring at room temperature at $\mathrm{pH} 4$. 


\subsection{Potentiometric Titrations}

Potentiometric titrations were carried out in the $\mathrm{pH}$ range 2-11 with an automatic titrator composed of a microprocessor buret Metrohm dosimat 665 and a pHmeter Metrohm 713 connected to a computer. The titration procedure was fully automated (12). All measurements were performed within a thermoregulated cell at $25.0 \pm 0.1^{\circ} \mathrm{C}$ under an argon stream to avoid the dissolution of carbon dioxide. The ionic strength was adjusted to 0.1 with $\mathrm{N}(\mathrm{Me}){ }_{4} \mathrm{Cl}$. The combined Type ' $\mathrm{U}$ ' glass electrode Metrohm used had a very low alkaline error. The $\mathrm{p} K_{\mathrm{w}}$ was fixed

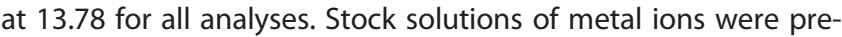
pared from analytical-grade salts $\left(\mathrm{GdCl}_{3}, 5.07 \times 10^{-2} \mathrm{moll}{ }^{-1}\right.$; $\mathrm{ZnCl}_{2}, 10^{-1} \mathrm{moll}^{-1} ; \mathrm{CaCl}_{2}, 7.97 \times 10^{-2} \mathrm{moll}^{-1}$; Aldrich 99.9\%]. The concentrations of each metal stock solution were determined by EDTA. Before their utilization, the mother solutions were diluted and ionic strength was adjusted to 0.1 with $\mathrm{N}(\mathrm{Me})$ ${ }_{4} \mathrm{Cl}$. Solutions of $\mathrm{L}=$ DTDTPA $\left(2 \times 10^{-3} \mathrm{moll}^{-1}\right)$ and Au@DTDTPA $\left(1.5 \times 10^{-3} \mathrm{moll}^{-1}\right)$ were titrated under Ar with standardized $\mathrm{N}$ $(\mathrm{Me})_{4} \mathrm{OH}$ solution $\left(5 \times 10^{-2} \mathrm{moll}^{-1}\right)$. For complexation studies, several ligand/metal ratios ([L]/[M]) were used: $1.05<[\mathrm{L}] /$ $[\mathrm{M}]<1.8$ (L=DTDTPA or Au@DTDTPA) and $8 \times 10^{-4}<[\mathrm{L}]<1.2 \times$ $10^{-3} \mathrm{~mol} \mathrm{~L}^{-1}$, each ratio being calculated on the basis of the concentrations of ligand and metal solutions previously determined, and their respective volumes. For each titration, the total volume in the cell was $4 \mathrm{ml}$.

The protometric data were processed using the PROTAF program (12) to obtain the best fit chemical model and refined overall constants $\beta_{\mathrm{mlh}}$ (except for the proton; the charges are not shown for clarity reasons):

$$
\begin{gathered}
\mathrm{mM}+\mathrm{eL}+\mathrm{hH}+\mathrm{M}_{\mathrm{m}} \mathrm{l}_{\ell} \mathrm{H}_{\mathrm{h}} \\
\beta_{\mathrm{mlh}}=\frac{\left[\mathrm{M}_{\mathrm{m}} \mathrm{L}_{\ell} \mathrm{H}_{\mathrm{h}}\right]}{[\mathrm{M}]^{\mathrm{m}}[\mathrm{L}]^{\ell}\left[\mathrm{H}^{+}\right]^{\mathrm{h}}}
\end{gathered}
$$

The stepwise protonation constants $\left(K_{\text {olh }}\right)$ related to equilibrium (II) and defined by equation (2) were deduced from the refined $\left(\beta_{\text {Oen }}\right)$ values by equation (3):

$$
\begin{gathered}
\mathrm{LH}_{\mathrm{h}-1}+\mathrm{H}^{+} \stackrel{K_{01 h}}{=} \mathrm{LH}_{\mathrm{h}} \\
K_{\text {Olh }}=\frac{\left[\mathrm{LH}_{\mathrm{h}}\right]}{\left[\mathrm{LH}_{\mathrm{h}-1}\right]\left[\mathrm{H}^{+}\right]} \\
\beta_{\text {Olh }}=\prod_{\mathrm{i}=1}^{h} \mathrm{~K}_{0 \ell i}
\end{gathered}
$$

Each titration used at least 150 points per neutralization curve, and titrations were repeated until a satisfactory agreement was reached. A minimum of 10 curves were used for the determination of the DTDTPA and Au@DTDTPA protonation constants. The titration data were fitted to a model of a ligand with six and five ionizable groups for DTDTPA and Au@DTDTPA respectively, using the program PROTAF (12). For the determination of the complexation constants, two curves were used for each $[\mathrm{L}] /[\mathrm{M}]$ ratio (leading to a minimum of 10 curves for each ligand). The stability constants were determined by analysis of the titration curves with PROTAF (12). The $\mathrm{Gd}^{3+}$ data was fit to a model containing three species, $\mathrm{GdLH}_{2}, \mathrm{GdLH}$ and $\mathrm{GdL}$. The $\mathrm{Zn}^{2+}$ data was modeled with five metal-ligand species - $\mathrm{ZnLH}_{3}, \mathrm{ZnLH}_{2}, \mathrm{ZnLH}$,
$\mathrm{ZnL}$ and $\mathrm{ZnL}(\mathrm{OH})$ - while the $\mathrm{Ca}^{2+}$ data was fitted to a model that considered five species $-\mathrm{CaLH}_{4}, \mathrm{CaLH}_{3}, \mathrm{CaLH}_{2}, \mathrm{CaLH}$ and $\mathrm{CaL}$. Speciation curves were obtained with HYSS program (28); afterwards log $\left[\left(M_{\text {free }}\right) /\left(M_{\text {total }}\right)\right]$ values were deduced under the following conditions: $[\mathrm{L}]=[\mathrm{M}]=2.0 \times 10^{-3} \mathrm{~mol} \mathrm{I}^{-1}$.

\subsection{Transmetallation Process}

The reactions of DTDTPA:Gd, Au@DTDTPA:Gd and DTPA:Gd with $\mathrm{Zn}^{2+}$ were monitored by measuring the longitudinal relaxation rates $R_{1}\left(1 / T_{1}\right)$ of water protons on a Bruker mq40 Minispec relaxometer $(0.94 \mathrm{~T})$, by the inversion recovery method. A $12.8 \mu \mathrm{l}$ aliquot of a $1.46 \times 10^{-1} \mathrm{moll}^{-1}$ solution of $\mathrm{ZnCl}_{2}$ was added to $750 \mu$ l of a phosphate-buffered $(\mathrm{pH} 7)$ solution of the paramagnetic complex $\left(2.5 \times 10^{-3} \mathrm{moll}^{-1}\right)$. The mixture was stirred and $75 \mu \mathrm{l}$ was taken off for relaxometry. The $R_{1 \mathrm{p}}$ relaxation rate was obtained after subtraction of the diamagnetic contribution of the proton water relaxation $\left(0.2656 \mathrm{~s}^{-1}\right)$ from the observed relaxation rate $R_{1 \mathrm{p}}^{\mathrm{t}}$. The temperature was equilibrated and maintained at $37^{\circ} \mathrm{C}$ during the experiments. In preliminary experiments, it was checked that the buffer itself was unable to extract $\mathrm{Gd}^{3+}$ from DTDTPA:Gd, Au@DTDTPA:Gd and DTPA:Gd respectively.

The rate of the reactions can be expressed as shown in equation (4):

$$
-\mathrm{d}[\mathrm{GdL}]_{t} / \mathrm{d} t=k_{\mathrm{obs}}[\mathrm{GdL}]_{t}
$$

where $[\mathrm{GdL}]_{t}$ is the total concentration of the complex ( $\mathrm{L}=\mathrm{DTDTPA}$, Au@DTDTPA, DTPA, respectively). Under our experimental conditions (phosphate buffer, $\mathrm{pH} 7$ ), the concentration of free $\mathrm{Zn}^{2+}$ is assumed to be approximately constant. Effectively, this concentration is ruled by the solubility constant of $\mathrm{Zn}_{3}\left(\mathrm{PO}_{4}\right)_{2}$ and as soon as $\mathrm{Zn}^{2+}$ is consumed by the transmetallation reaction it is regenerated by dissolution of $\mathrm{Zn}_{3}\left(\mathrm{PO}_{4}\right)_{2}$ (24). Consequently, the rate of transmetallation $k_{\text {obs }}$ was determined using equation (5), where $R_{1 \mathrm{p}}^{0}, R_{1 \mathrm{p}}{ }^{t}$ and $R_{1 \mathrm{p}}^{\mathrm{e}}$ are the relaxation rate values at the start, at time $t$ and at equilibrium of the reaction:

$$
R_{1 \mathrm{p}}{ }^{\mathrm{t}}=R_{1 \mathrm{p}}{ }^{\mathrm{e}}+\left(R_{1 \mathrm{p}}{ }^{0}-R_{1 \mathrm{p}}{ }^{\mathrm{e}}\right) \exp \left(-k_{\mathrm{obs}} t\right)
$$

\subsection{NMRD Profile}

${ }^{1} \mathrm{H}$ NMRD profiles were measured on a Stelar Spinmaster FFC fast field cycling NMR relaxometer (Stelar, Mede, Pavia, Italy) over a range of magnetic fields extending from $0.24 \mathrm{mT}$ to $0.7 \mathrm{~T}$ and corresponding to ${ }^{1} \mathrm{H}$ Larmor frequencies from 0.01 to $40 \mathrm{MHz}$ using $0.6 \mathrm{ml}$ samples in $10 \mathrm{~mm}$ o.d. tubes. The temperature was kept constant at $37^{\circ} \mathrm{C}$. The additional relaxation rate at $60 \mathrm{MHz}$ was obtained with a Bruker Minispec mq60 spectrometer (Bruker, Karlsruhe, Germany).

\section{Acknowledgements}

V. Mogilireddy thanks the Region Champagne Ardenne for her doctoral fellowship. Agathe Martinez is gratefully acknowledged for her help in ${ }^{1} \mathrm{H}$ NMR titration. Financial support by CNRS, Conseil Regional Champagne Ardenne, Conseil General de la Marne, Ministry of Higher Education and Research and EU-programme FEDER to the PIAneT CPER project is gratefully acknowledged. S.L., L.V.E. and R. M thank the Walloon Region, the FNRS, the IUAP VII and the ARC programs. 


\section{REFERENCES}

1. Vande Velde G, Baekelandt V, Dresselaers T, Himmelreich U. Magnetic resonance imaging and spectroscopic methods for molecular imaging. Q J Nucl Med Mol Imaging 2009; 53: 565-585.

2. Weissleder R, Ross BD, Rehemtulla A, Gambhir SS. Molecular Imaging, Principles and Practice. People's Medical Publishing House: USA, 2010.

3. Hahn MA, Singh AK, Sharma P, Brown SC, Moudgil BM. Nanoparticles as contrast agents for in-vivo bioimaging: current status and future perspectives. Anal Bioanal Chem 2011; 399: 3-27.

4. Aime S, Delli Castelli D, Geninatti Crich S, Gianolio E, Terreno E. Pushing the sensitivity envelope of lanthanide-based magnetic resonance imaging (MRI) contrast agents for molecular imaging applications. Acc Chem Res 2009; 42: 822-831.

5. Hainfeld JF, Slatkin DN, Focella TM, Smilowitz HM. Gold nanoparticles: a new X-ray contrast agent. Br J Radiol 2006; 79: 248-253.

6. Debouttière $P J$, Roux $S$, Vocanson $F$, Billotey $C$, Beuf $O$, FavreRéguillon $A$, Lin Y, Pellet-Rostaing $S$, Lamartine R, Perriat $P$, Tillement O. Design of gold nanoparticles for magnetic resonance imaging. Adv Funct Mater 2006; 16: 2330-2339.

7. Alric C, Taleb J, Le Duc G, Mandon C, Billotey C, Le Meur-Herland A, Brochard T, Vocanson V, Janier M, Perriat P, Roux S, Tillement $O$. Gadolinium chelate coated gold nanoparticles as contrast agents for both X-ray computed tomography and magnetic resonance imaging. J Am Chem Soc 2008; 130: 5908-5915.

8. Arifin DR, Long CM, Gilad AA, Alric C, Roux S, Tillement O, Link TW, Arepally A, Bulte JW. Trimodal gadolinium-gold microcapsules containing pancreatic islet cells restore normoglycemia in diabetic mice and can be tracked by using US, CT, and positive-contrast MR imaging. Radiology 2011; 260: 790-798.

9. Brust M, Fink J, Bethell D, Schiffrin DJ, Kiely C. Synthesis and reactions of functionalised gold nanoparticles. J Chem Soc Chem Commun 1995; 1655-1656.

10. Sherry AD, Cacheris WP, Kuan KT. Stability constants for $\mathrm{Gd}^{3+}$ binding to model DTPA-conjugates and DTPA-proteins: implications for their use as magnetic resonance contrast agents. Magn Reson Med 1988; 8: 180-190.

11. Laurent S, Vander Elst L, Henoumont C, Muller RN. How to measure the transmetallation of a gadolinium complex. Contrast Media Mol Imaging 2010; 5: 305-308.

12. Fournaise R, Petitfaux C. Etude de la formation des complexes en solution aqueuse - III. Nouvelle méthode d'affinement des constantes de stabilité des complexes et des autres paramètres des titrages protométriques. Talanta 1987; 34: 385-395.

13. Geraldes CFGC, Urbano AM, Alpoim MC, Sherry AD, Kuan KT, Rajagopalan R, Maton F, Muller RN. Preparation, physico-chemical characterization, and relaxometry studies of various gadolinium(III)DTPA-bis(amide) derivatives as potential magnetic resonance contrast agents. Magn Reson Imaging 1995; 13: 401-420.

14. Martell AE, Smith RM. Critical Stability Constants. vol. 4. Plenum: New York, 1974.

15. Leussing DL, Albert GS. The reactions of nickel(11) with 1,2-ethanedithiol. J Am Chem Soc 1960; 82: 4458-4461.

16. Crisponi G, Diaz A, Nurchi VM, Pivetta T, Tapia Estevez MJ. Equilibrium study on $\mathrm{Cd}(\mathrm{II})$ and $\mathrm{Zn}$ (II) chelates of mercapto carboxylic acids. Polyhedron 2002; 21: 1319-1327.
17. Bianchi A, Escuder B, Garcia-Espana E, Luis SV, Marcelino V, Miravet JF, Ramirez JA. Protonation tendencies of azaparacyclophanes. A thermodynamic and NMR Study. J Chem Soc Perkin Trans 2 1994; 10: $1253-1259$.

18. Kim HK, Jung HY, Park JA, Huh MI, Jung JC, Chang Y, Kim TJ. Gold nanoparticles coated with gadolinium-DTPA-bisamide conjugate of penicillamine (Au@GdL) as a T1-weighted blood pool contrast agent. J Mater Chem 2010; 20: 5411-5417.

19. Kimura K, Takashima S, Ohshima S. Molecular approach to the surface potential estimate of thiolate-modified gold nanoparticles. J Phys Chem B 2002; 106: 7260-7266.

20. Baranyai Z, Gianolio E, Ramalingam K, Swenson R, Ranganathan R, Brucher $\mathrm{E}$, Aime $\mathrm{S}$. The effects of intramolecular H-bond formation on the stability constant and water exchange rate of the $\mathrm{Gd}(\mathrm{III})$ diethylenetriamine- $\mathrm{N}^{\prime}$-(3-amino-1, 1-propylenephosphonic)- $\mathrm{N}, \mathrm{N}^{\prime}$, "tetracetate complex. Contrast Media Mol Imaging 2007; 2: 94-102.

21. Garcés LJ, Castro CR, David C, Madurga S, Mas F, Pastor I, Puy J. Model-independent link between the macroscopic and microscopic descriptions of multidentate macromolecular binding;relationship between stepwise, intrinsic and microscopic equilibrium constants. J Phys Chem B 2009; 113: 15145-15155.

22. Lacerda S, Campello MP, Marques F, Gano L, Kubicek V, Fouskova P, Toth E, Santos I. A novel tetraazamacrocycle bearing a thiol pendant arm for labeling biomolecules with radiolanthanides. Dalton Trans 2009; 4509-4518.

23. Sarka $L$, Burai $L$, Brucher $E$. The rates of the exchange reactions between $\left[\mathrm{Gd}(\mathrm{DTPA}]^{2-}\right.$ and the endogenous ions $\mathrm{Cu}^{2+}$ and $\mathrm{Zn}^{2+}: \mathrm{a}$ kinetic model for the prediction of the in vivo stability of [Gd $(\mathrm{DTPA}]^{2-}$, used as a contrast agent in magnetic resonance imaging. Chem Eur J 2000; 6: 719-724.

24. Idée JM, Port M, Raynal I, Schaefer M, Le Greneur S, Corot C. Clinical and biological consequences of transmetallation induced by contrast agents for magnetic resonance imaging: a review. Fundam Clin Pharmacol 2006; 20: 563-576.

25. Laurent S, Vander Elst L, Copoix F, Muller RN. Stability of MRI paramagnetic contrast media. A proton relaxometric protocol for transmetallation assessment. Invest Radiol 2001; 36: 115-122.

26. Gu S, Kim HK, Lee GH, Kang BS, Chang Y, Kim TJ. Gd-complexes of 1,4,7,10-Tetraazacyclododecane-N, $\mathrm{N}^{\prime}, \mathrm{N}^{\prime \prime}, \mathrm{N}^{\prime \prime}-1,4,7,10$-tetraacetic acid (DOTA) conjugates of tranexamates as a new class of blood-pool magnetic resonance imaging contrast agents. J Med Chem 2011; 54: $143-152$.

27. Jaszberenyi Z, Banyai I, Brucher E, Kiraly R, Hideg K, Kalai T. Equilibrium and NMR studies on GdIII, YIII, Cull and Znll complexes of various DTPA-N,N-bis(amide) ligands. Kinetic stabilities of the gadolinium(III) complexes. Dalton Trans 2006; 1082-1091.

28. Alderighi L, Gans P, lenco A, Peters D, Sabatini A, Vacca A. Hyperquad simulation and speciation (HySS): a utility program for the investigation of equilibria involving soluble and partially soluble species. Coord Chem Rev 1999; 184: 311-318.

\section{SUPPORTING INFORMATION}

Additional supporting information may be found in the online version of this article at the publisher's web site. 